\title{
VA Experience in Implementing Patient-Centered Medical Home Using a Breakthrough Series Collaborative
}

\author{
Balmatee Bidassie, $P h D^{7}$, Michael L. Davies, $M D^{2}$, Richard Stark, MD³, and Barbara Boushon, RN, \\ $B S N^{7}$
}

${ }^{1}$ Clinical Partnerships in Healthcare Transformation (CPHT), VA Center for Applied Systems Engineering (VA-CASE), VISN 11 - Veterans Engineering Resource Center (VERC), Detroit, MI, USA; ${ }^{2}$ Office of Access and Clinic Administration, Washington DC, USA; ${ }^{3}$ Primary Care Operations, Washington DC, USA.

\begin{abstract}
BACKGROUND: Veterans Health Administration (VHA) seeks to improve the delivery of patientcentered care. A Patient-Centered Medical Home (PCMH) Model, named Patient Aligned Care Team (PACT), was implemented to transform the VHA primary care delivery process. VHA used a collaborative learning model as a key approach to disseminate PACT concepts and changes.
\end{abstract}

OBJECTIVE: To describe and examine VHA's experience disseminating PACT transformation using a Breakthrough Series Collaborative method.

DESIGN: Observational study.

PARTICIPANTS: Approximately 250-350 individuals from 141 teams participated in six face-to-face learning sessions across 21 months.

MAIN MEASURES: 1) PACT Collaborative participant surveys; 2) Coach Assessment Scores and Plan-DoStudy-Act (PDSA) data; and 3) PACT Compass (national measures to assess PACT implementation within VA healthcare system).

KEY RESULTS: A majority of the participants indicated that the PACT Collaborative was necessary to implement PACT. The number of PDSAs increased steadily during the Collaborative period; $93 \%$ ( $n=$ 1,547) of PDSAs were successfully implemented. Teams successfully achieved over $80 \%$ of their aims, which were highly correlated with PDSAs implemented $\left(R^{2}=0.88\right)$. The most successful aims achieved were offering same-day appointments, increasing non-face-to-face care, and improving team communication. PACT Compass indicated an improvement after the Collaborative ( $p$-value $<.000)$, and providers observed differences in their care practice ( $p$-value $<$ 0.002). This positive impact may be due to the spread of the PACT Model through the PACT Collaborative, among other learning initiatives.

CONCLUSIONS: For complex collaborative models such as PACT, more than three learning sessions may be required. As VHA continues to disseminate the PACT Model through primary care, into specialty/surgical

Electronic supplementary material The online version of this article (doi:10.1007/s11606-014-2773-5) contains supplementary material, which is available to authorized users.

Published online April 9, 2014 care and beyond, the Collaborative Learning Model may continue to be an effective way to leverage a small number of faculty, coaches, and industrial engineers across an extremely large population.

KEY WORDS: access; medical home; PACT; patient-centric; collaborative.

J Gen Intern Med 29(Suppl 2):S563-71

DOI: $10.1007 / \mathrm{s} 11606-014-2773-5$

(C) Society of General Internal Medicine 2014

\section{INTRODUCTION}

Since its inception ${ }^{1}$ in the early 1990 s, primary care has been the entry point to coordinated care for Veterans, offering long-term relationships with specialists and providers in the Veterans Health Administration (VHA) http:// www.who.int/topics/primary_health_care/en/.,3,4 Although the VHA primary care system has been called "The Best Care Anywhere," accessing such care can be complex, unreliable, and dissatisfying for Veterans. ${ }^{6}$ As a result, transformation to a more patient-centered culture is a top VHA organizational priority.

The Patient-Centered Medical Home (PCMH) Mod$\mathrm{el}^{7,8,9,10,11,12,13}$ is a systematic approach to coordinating and integrating services that ensures optimal value and health outcomes. Based on Veterans' feedback, VHA developed their version of the PCMH Model, called "Patient Aligned Care Team" (PACT), to improve Veteran experience, staff satisfaction, and quality of primary care. $^{14,15,16}$ To address the challenge of implementing PACT in an estimated 7,200 VHA practices at approximately 1,700 sites, VHA strategically designed and implemented a Collaborative involving PACT leadership and front-line teams from every medical center (approximately 1,500 participants) over a 21 -month period. This manuscript describes the VHA's experience utilizing the Collaborative method to spread the PACT Model-including methods of evaluation, results, and 
lessons learned - in order to provide information to others considering wide-scale improvement initiatives.

\section{PACT (MEDICAL HOME) MODEL}

After reviewing PCMH literature and standards, ${ }^{17,18,19,20,21,22}$ the national VHA leadership team created a PACT conceptual model designed as a "house" (Fig. 1) to guide and facilitate improvement efforts. The foundation is based on a patientcentered approach, critical resources, and Vision-AnalysisTeam-Aim-Map-Measure-Change-Sustain (VA-TAMMCS) improvement framework ${ }^{23}$ (Appendix A; all appendixes available online). The model has three pillars: 1) Access; 2) Care Coordination and Management; and 3) Practice Redesign. The respective goals of the pillars are to: 1) achieve optimal access by offering patients single or group appointments and non-appointment options; 2) ensure that high-risk transitions, or "hand-overs," are managed appropriately, providing a continuous link with core teams even when care is provided at a facility away from the primary care location; and 3) improve communication and work processes, ensuring the right person does the right work at the right time. Teams were required to achieve seven aims with associated measures (Appendix B). Industrial engineers (IEs) and coaches assisted with map and measure processes, and improvement potentials within each pillar. Teams were given many resources (Table 1), such as a "change package" providing suggestions for improvement within each pillar (Appendix C).
This study is an exploratory evaluation of VA's PACT Collaborative, a major component of VA's national PACT implementation strategy. This evaluation asks whether participants found the Collaborative process useful, whether participants carried out the Collaborative's improvement activities and achieved its aims, and whether adherence to the PACT model improved nationally during the Collaborative period.

\section{PACT COLLABORATIVE INTERVENTION METHODS PACT Collaborative Model}

PACT Collaborative was modeled after the Institute for Healthcare Improvement's (IHI) Breakthrough Series (BTS) Collaborative Model $^{24,25}$ (Appendix D). A National Collaborative Leadership Team (NCLT) designed the intervention by considering resource constraints, complexity, scale of desired change, and anticipated time required to make changes.

Participants. The NCLT divided all VHA facilities into five regions (26-33 hospitals each) and provided guidance on identifying teams at each facility (seven to nine member) to travel to their regional PACT Collaborative. Teams (Appendix E) were comprised of leadership (i.e. associate chief of staff/nurse manager/service line manager for Primary Care) and direct-care staff (i.e. MD, RN, LPN/ MOA, clerical staff and pharmacy, social work and behavioral health staff, as appropriate).

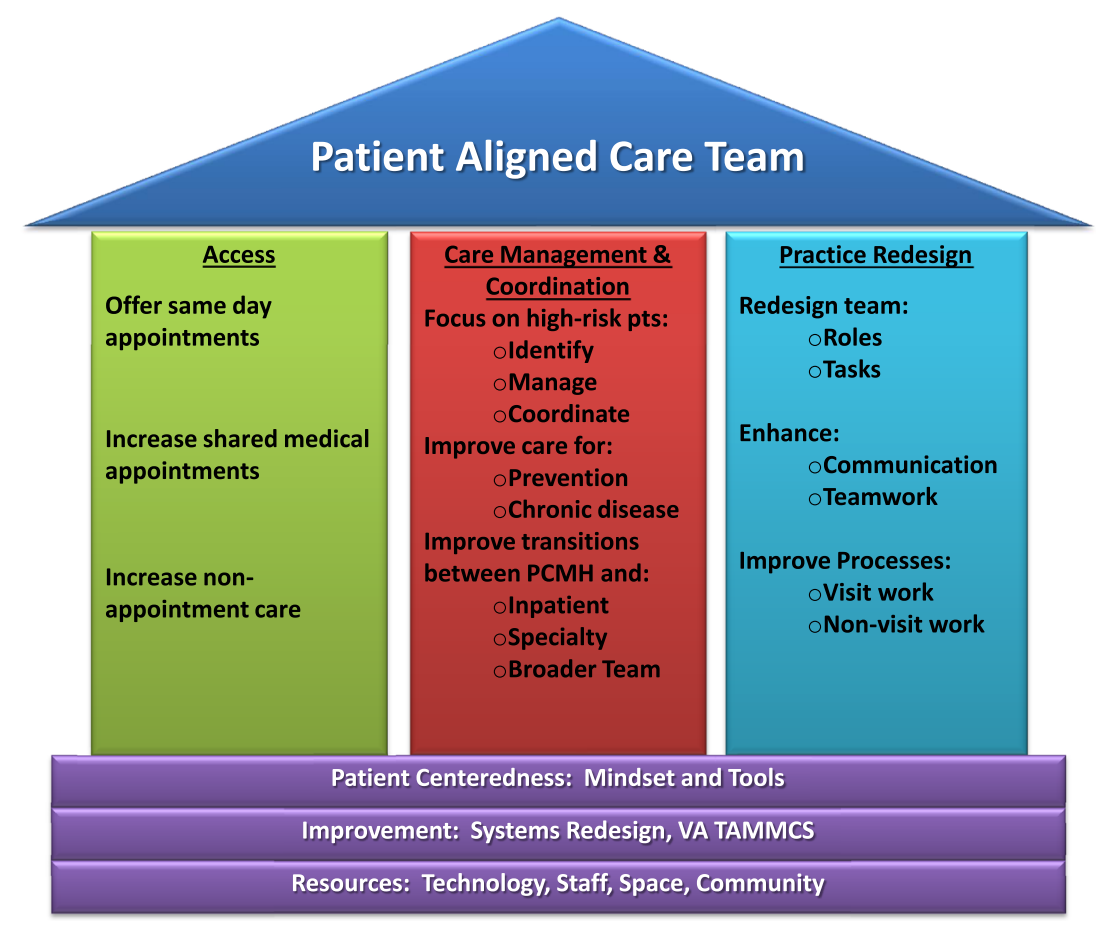

Figure 1. PACT (Medical Home) Model. 
Table 1. PACT Collaborative Resources (People, Tools, and Technology)

\begin{tabular}{|c|c|}
\hline People & Tools and technology \\
\hline $\begin{array}{l}\text { - Collaborative directors } \\
\text { (provide over-arching direction, } \\
\text { goals, overall progress for } \\
\text { Collaborative, share expertise } \\
\text { with teams, and lead new } \\
\text { learning content development } \\
\text { efforts) } \\
\text { - VERC-VHA collaborative } \\
\text { coordinators (coordinate Col- } \\
\text { laborative events, collect team } \\
\text { information, update Microsoft } \\
\text { SharePoint Library, and develop } \\
\text { learning content) } \\
\text { - Clinical coaching (formal } \\
\text { support or coaching offered to } \\
\text { assist with PACT-related efforts; } \\
\text { provide feedback on team re- } \\
\text { ports regularly) } \\
\text { - VERC industrial engineer } \\
\text { (one IE aligned with a region to } \\
\text { support clinician coaches and } \\
\text { teams on measurement tool, } \\
\text { PDSA and monthly reports) }\end{array}$ & $\begin{array}{l}\text { - Prework guide (guide of PACT } \\
\text { principles and applicable content } \\
\text { teams can use as a resource) } \\
\text { - PACT collaborative change } \\
\text { package (key principles and } \\
\text { strategies organized by Pillar to } \\
\text { assist teams in their work in the } \\
\text { Collaborative) } \\
\text { - Data tracking and process } \\
\text { monitoring tools } \\
\text { Standardized measurement } \\
\text { tools (Excel-based tools are based } \\
\text { on data extracted manually from } \\
\text { patient treatment records, and } \\
\text { provide summary statistics and } \\
\text { trend graphs developed for each } \\
\text { Pillar to capture data and produce } \\
\text { graphs) created to support stan- } \\
\text { dardized data collection for PACT } \\
\text { Collaborative aims. } \\
\text { Reports (monthly reports to } \\
\text { update Collaborative Directors, } \\
\text { Coordinators, and Coaches on } \\
\text { work and aims progress) } \\
\text { - Cross-functional communica- } \\
\text { tion } \\
\text { Microsoft sharepoint library } \\
\text { (venue for sharing resources, ma- } \\
\text { terials, team reports, and presen- } \\
\text { tations) } \\
\text { Regional livemeeting/confer- } \\
\text { ence calls (venue to present work, } \\
\text { receive coaching, and learn what } \\
\text { others are doing) }\end{array}$ \\
\hline
\end{tabular}

VERC Veterans Engineering Resource Center

Coaches and Faculty. The NCLT recruited regional codirectors, co-coordinators, coach captains, faculty and coaches predominately from VHA with outstanding leadership and teaching skills, who participated in past national improvement programs, and agreed to lead the effort as a collateral duty. Five IEs and five coordinators (one for each region) were recruited from the Veteran Engineering Resource Centers to serve as coaching, teaching, and process improvement experts. Based on the Collaborative's seven aims, the IEs developed standardized measurement tools (in Microsoft EXCEL) to collect data, track improvement progress, and make process improvement decisions. Most of the Collaborative leadership had no prior experience leading a collaborative; therefore, NCLT offered just-in-time training and resources. Most of the IEs had limited experience with healthcare, so they were partnered with VHA coaches to provide a more effective coaching experience for the teams. Each of the five regions identified a "coach captain" to be the master-level resource for approximately ten coaches per region. They led teaching calls, answered questions, problem-solved, and provided feedback.

Setting. Learning Sessions (LSs) were the major integrative events of the Collaborative, where new material was introduced, past material was reviewed, questions were answered, best practices were shared, and action plans were made. Prior to the
LSs, the seven aims were shared with participants at the prework $^{26}$ stage. Due to the complexity of PACT, the NCLT decided on six strategically timed LSs (compared to 3-4 in the IHI model). The regional Collaborative leadership planned and held six 3-day, face-to-face LSs, each in a different city within the five regions (totaling 30 LSs nationally) from June 2010 through February 2012 (Fig. 2).

To keep the regional Collaborative consistent with the national plan, approximately $80 \%$ of agenda content was consistent across all regions, while $20 \%$ was elective content planned by regional leadership. NCLT conducted bi-monthly calls to plan, educate and guide regional leadership. Across each region, PACT material was introduced sequentially, with LS1 focusing on the first pillar, LS2 reviewing the first pillar and introducing the second pillar, and so forth. LSs were highly interactive, including selected team reports, topical small group breakouts, activities, posters, and audience feedback system sessions. Key national faculty traveled to all 30 LSs across all five regions.

Action Periods (between LSs) were equally important. After each LS, all teams tested and implemented Plan-DoStudy-Act (PDSA) cycles of change identified during LSs, and performed "teach back" of PACT concepts to members of "home" teams who did not travel to the LSs. The PDSA Cycle consists of: 1) Plan the test or observation, including collecting data; 2) Do/try the test on a small scale; 3) Study the results and analyze the data; and 4) Act, or refine the change based on what was learned from the test. All teams were assigned two coaches (Clinical and IE) who assisted them with these PDSAs to achieve their seven aims. Teams used standard monthly reports to describe narrative and numerical progress (trend graphs standardized measurement tools). IEs also collected Collaborative tools to be included in the national "PACT Toolkit," 27 which served as the virtual vehicle to spread ideas to other teams.

\section{PACT COLLABORATIVE EVALUATION METHODS Measures of Team Performance: Coach Assessment Score and PDSA Analysis}

Each team was expected to attend all six LSs and participate in coach-facilitated monthly phone calls and weekly team meetings. Teams were required to adopt the seven aims and associated measures, and submit monthly written reports. Assigned coaches and IEs provided feedback and assessed progress based on narrative descriptions and graphs from the standardized measurement tools. IEs and coaches assessed each of the 141 teams' monthly reports to identify, collect, and categorize teams' PDSAs and progress toward their aims. The clinical coaches assigned a score reflecting progress for each of the seven aims based on the IHI Collaborative Assessment Scale $^{28}$ (Appendix F). The 


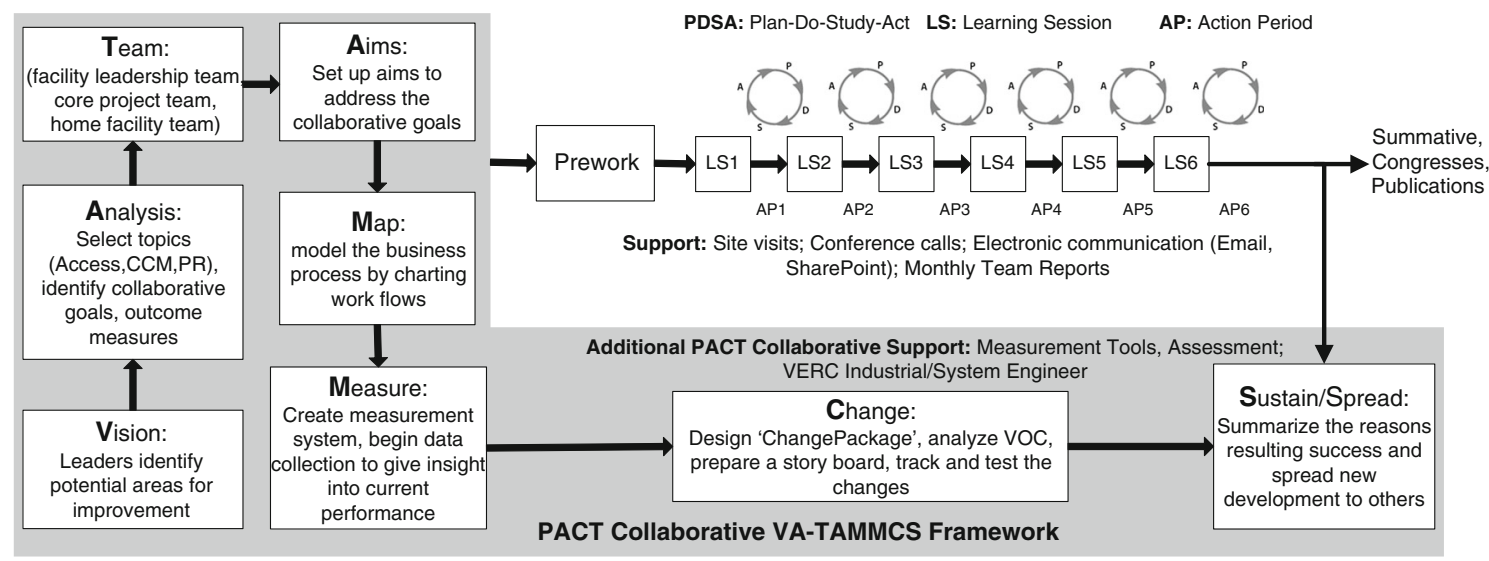

Note: Based on the Institute for Healthcare Improvement Breakthrough Series model* enhanced with VA-TAMMCS framework

*Institute for Healthcare Improvement. The Breakthrough Series: IHI’s Collaborative Model for Achieving Breakthrough Improvement. 2003.

Figure 2. Schematic of the PACT Collaborative Model.

stated goal was to achieve the aims (represented by a score of "4").

\section{VHA Measures: PACT Compass \& ACP Medical Home Builder Survey}

PACT Compass metrics from VHA's information systems were obtained and organized in broad domains, such as access, coordination of care, and continuity. The American College of Physicians $\left(\mathrm{ACP}^{\circledR}\right)$ Medical Home Builder Survey, ${ }^{29}$ was initially conducted in October 2009 (preCollaborative) and repeated in July 2011 (during the Collaborative). It provides data on patient care, organization, and workflow status, and, when administered sequentially, overall practice improvement (Appendix G).

Insights on PACT Collaborative: Data Collection Survey. While the monthly reports, standardized measurement tools, and PACT Compass provided an assessment on the effectiveness of PDSA activities to achieve the Collaborative aims, surveys were used for participants to share insights on lessons learned, participants' satisfaction, learning, skill acquisition, and perceived barriers and enablers of PACT implementation (Appendix H). Participants were asked to complete a survey after each regional LS, and two online "follow-up surveys"30 (Appendix I) were administered approximately 90 days after LS4 and LS6.

\section{ANALYSIS}

Data analysis was conducted in SPSS 16.0. One-way ANOVA provided a common mean and identified statistical differences in the comparison of PACT Compass Measures before, during, and after the PACT Collaborative. A $p$-value less than 0.05 identifies less than a $5 \%$ chance that the identified statistical differences were due to chance. Descriptive statistics and means scores were used to describe the coach assessment score and survey results (four point scale).

\section{RESULTS}

\section{Measures of Team Performance: Coach Assessment Score/PDSA Analysis}

Based on the 1,670 attempted PDSAs collected from 3,186 monthly reports, $93 \%(n=1547)$ of PDSAs were successfully implemented; $2 \%(n=29)$ were abandoned; and $6 \%(n=94)$ were work-in-progress. Eighty-one percent $(n=1253)$ of successful PDSAs (across all regions) focused on nine principles. Teams attempted to reduce demand and balance supply-and-demand for appointments to improve access and transitions, focus on high-risk patients, create an infrastructure to manage and coordinate care, anticipate patients' needs, synchronize visit start times, and optimize environments/ improve efficiency to improve practice function (Appendix J). Table 2 and Fig. 3 summarize the coach assessment score. Teams achieved the most success in offering same-day appointments, increasing non-face-to-face care, improving team communication, identifying and actively managing high-risk patients, and starting appointments within $10 \mathrm{~min}$ of scheduled times. Improving handovers with inpatient and specialty care were the most challenging aims.

\section{VHA Measures: PACT Compass \& ACP Medical Home Builder Survey}

Assessment of PACT Compass metric performance of teams participating directly in the Collaborative is beyond 
Table 2. Summary of Coach Assessment Score at End of PACT Collaborative by Pillar and Aims

\begin{tabular}{|c|c|c|c|c|c|c|c|c|}
\hline & \multirow[t]{2}{*}{ Pillar/ Aims } & \multicolumn{2}{|c|}{ Access } & \multicolumn{3}{|c|}{$\begin{array}{l}\text { Care Coordination and } \\
\text { Management }\end{array}$} & \multicolumn{2}{|c|}{$\begin{array}{l}\text { Practice } \\
\text { Redesign }\end{array}$} \\
\hline & & A1 & A2 & CCM1 & ССМ2 & CCM3 & PR1 & PR2 \\
\hline \multirow[t]{2}{*}{ Exemplar teams (*Scoring at least 4.0$)$} & $\mathrm{n}$ & 75 & 80 & 74 & 61 & 34 & 74 & 107 \\
\hline & $\%$ & $53 \%$ & $57 \%$ & $52 \%$ & $43 \%$ & $24 \%$ & $53 \%$ & $77 \%$ \\
\hline \multirow[t]{2}{*}{ Work-in-progress teams (*Scoring $3.0-3.5$ ) } & $\mathrm{n}$ & 51 & 47 & 42 & 50 & 35 & 43 & 23 \\
\hline & $\%$ & $35 \%$ & $33 \%$ & $29 \%$ & $35 \%$ & $24 \%$ & $30 \%$ & $16 \%$ \\
\hline \multirow[t]{2}{*}{ Low-score teams (*Scoring at most 2.5$)$} & $\mathrm{n}$ & 15 & 13 & 25 & 29 & 71 & 23 & 9 \\
\hline & $\%$ & $10 \%$ & $9 \%$ & $17 \%$ & $20 \%$ & $49 \%$ & $16 \%$ & $6 \%$ \\
\hline
\end{tabular}

AIMS:

A1: Offer same day appointments

A2: Increase non-face to face care

CCM1: Identify and actively manage high risk patients

CCM2: Improve handovers with inpatient

CCM3: Improve handovers with specialty

PR1: Start appointments within 10 mins of scheduled time

PR2: Improve team communication

*Scoring 1-5 scale:

$4.0=$ Achieved Aims

$3.0=$ Several successful tests of change with outcomes

$3.5=$ Testing multiple changes; measurable progress over $>3$ data points

$2.5=$ Tests of change begun, no measurable Progress

*Based on the Institute for Healthcare Improvement Breakthrough Series Model Assessment Scoring 1-5 scale (Appendix F)

the scope of this paper. Instead, we focused on the Collaboratives as a national program with potential indirect as well as direct effects. Data sets for October of FY2010 to December of FY2012 were analyzed to capture change in PACT Compass performances during the pre-Collaborative, Collaborative, and post-Collaborative periods. Table 3 (below) indicates that there was a statistically significant improvement in $\mathrm{ACP}^{\circledR}$ Medical Home Builder modules during the Collaborative period compared to 'before the Collaborative' period. Also, there were statistically significant increases in average performance in each of the following eight measures: 1) percentage of patients seen in primary care within 7 days; 2 )

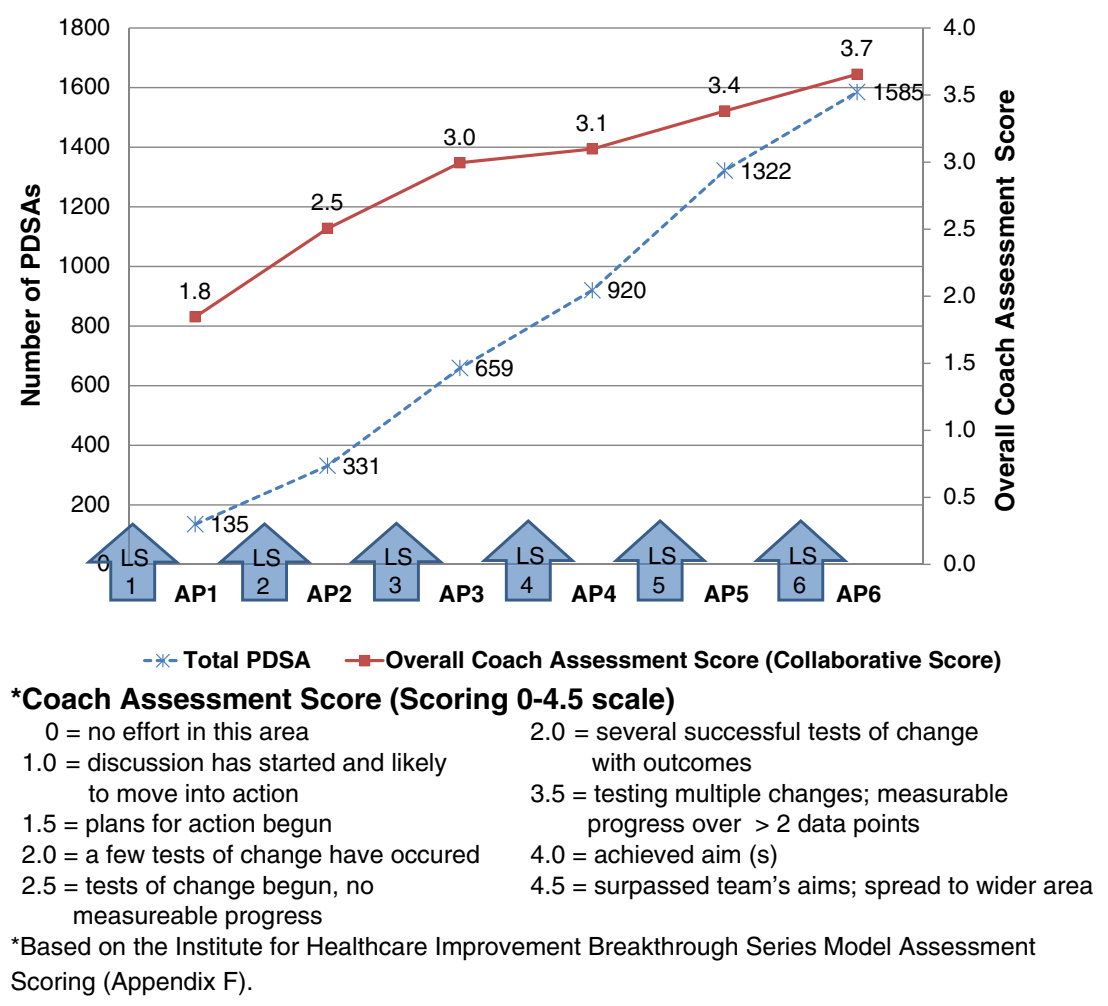

Figure 3. Trend of cumulative PDSAs and overall Coach Assessment Score across the six learning sessions. 
Table 3. Comparison of PACT Compass Measures Before, During and After PACT Collaborative

\begin{tabular}{|c|c|c|c|c|c|c|c|c|c|c|c|}
\hline \multirow[b]{2}{*}{ PACT Compass } & & \multirow[b]{2}{*}{ Mean } & \multirow[b]{2}{*}{$\begin{array}{l}\text { Std. } \\
\text { Deviation }\end{array}$} & \multirow[b]{2}{*}{$\begin{array}{l}\text { Std. } \\
\text { Error }\end{array}$} & \multicolumn{2}{|c|}{$\begin{array}{l}95 \% \text { Confidence } \\
\text { Interval for Mean }\end{array}$} & \multirow[b]{2}{*}{ Minimum } & \multirow[b]{2}{*}{ Maximum } & \multirow[b]{2}{*}{ df } & \multirow[b]{2}{*}{$\mathbf{F}$} & \multirow[b]{2}{*}{ p-value } \\
\hline & & & & & $\begin{array}{l}\text { Lower } \\
\text { Bound }\end{array}$ & $\begin{array}{l}\text { Upper } \\
\text { Bound }\end{array}$ & & & & & \\
\hline ALL PC $\mathrm{Pt} \%$ & Pre-PACT & 85.42 & 1.85 & 0.24 & 84.94 & 85.90 & 81.90 & 88.60 & 2 & 111.17 & $* * *$ \\
\hline seen in primary & PACT & 87.69 & 2.03 & 0.20 & 87.29 & 88.09 & 82.70 & 92.00 & & & \\
\hline $\begin{array}{l}\text { care within } 7 \text { day } \\
\text { of DD } \\
\text { (excluding C\&P) }\end{array}$ & Post_PACT & 90.23 & 1.73 & 0.20 & 89.84 & 90.62 & 86.80 & 93.60 & & & \\
\hline Same day & Pre-PACT & 43.42 & 5.95 & 0.77 & 41.88 & 44.96 & 32.90 & 54.20 & 2 & 101.40 & $* * *$ \\
\hline Appts w/PC & PACT & 50.73 & 7.16 & 0.71 & 49.32 & 52.14 & 36.10 & 69.80 & & & \\
\hline provider ratio & Post PACT & 59.69 & 6.72 & 0.76 & 58.18 & 61.21 & 46.30 & 70.50 & & & \\
\hline Primary care & 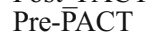 & 293.88 & 268.20 & 34.62 & 224.59 & 363.16 & 4.00 & 966.75 & 2 & 7.10 & $0.001 * *$ \\
\hline group & PACT & 399.91 & 338.06 & 33.47 & 333.51 & 466.31 & 7.00 & 1269.25 & & & \\
\hline encounters & Post PACT & 513.87 & 393.42 & 44.55 & 425.16 & 602.57 & 10.00 & 1414.00 & & & \\
\hline Ratio of PC & Pre-PACT & 3.76 & 0.77 & 0.10 & 3.56 & 3.96 & 2.60 & 6.30 & 2 & 452.52 & $* * *$ \\
\hline telephone & PACT & 12.78 & 7.09 & 0.70 & 11.39 & 14.18 & 2.70 & 27.50 & & & \\
\hline $\begin{array}{l}\text { encounters to } \\
\text { all PC }\end{array}$ & Post_PACT & 27.90 & 2.24 & 0.25 & 27.39 & 28.40 & 21.30 & 32.70 & & & \\
\hline encounters & & & & & & & & & & & \\
\hline Total inbound & Pre-PACT & 121.98 & 173.47 & 27.43 & 66.50 & 177.45 & 10.50 & 588.00 & 2 & 128.56 & $* * *$ \\
\hline PC secure & PACT & 698.34 & 831.78 & 82.77 & 534.14 & 862.55 & 1.00 & 3132.80 & & & \\
\hline messages & Post_PACT & 4883.51 & 3090.49 & 349.93 & 4186.71 & 5580.30 & 62.00 & 12528.00 & & & \\
\hline Total outbound & Pre-PACT & 124.15 & 178.54 & 28.23 & 67.04 & 181.25 & 7.50 & 616.00 & 2 & 125.49 & $* * *$ \\
\hline PC secure & PACT & 609.98 & 676.65 & 67.33 & 476.40 & 743.56 & 1.00 & 2440.80 & & & \\
\hline messages & Post PACT & 3956.43 & 2505.77 & 283.72 & 3391.47 & 4521.40 & 52.00 & 10029.00 & & & \\
\hline 2 day contact & Pre-PACT & 6.53 & 1.06 & 0.14 & 6.25 & 6.80 & 5.10 & 9.20 & 2 & 938.34 & $* * *$ \\
\hline post discharge & PACT & 17.56 & 10.39 & 1.03 & 15.52 & 19.60 & 5.30 & 41.20 & & & \\
\hline ratio- VHA D/C & Post PACT & 56.90 & 5.28 & 0.60 & 55.71 & 58.09 & 39.50 & 64.20 & & & \\
\hline Satisfaction - & 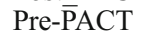 & 3.78 & 0.06 & 0.02 & 3.72 & 3.84 & 3.66 & 3.81 & 2 & 5.52 & $0.016^{*}$ \\
\hline primary care & PACT & 3.79 & 0.05 & 0.02 & 3.73 & 3.84 & 3.70 & 3.84 & & & \\
\hline Avg & Post_PACT & 3.68 & 0.07 & 0.03 & 3.61 & 3.75 & 3.55 & 3.74 & & & \\
\hline
\end{tabular}

same-day appointment with primary care provider ratio; 3) primary care group encounters; 4) ratio of primary care telephone encounters to all primary care encounters; 5) total inbound primary care secure messages; 6) total outbound primary care secure messages; 7) second-day contact post-discharge; and 8) average primary care staff satisfaction.

Insights on PACT Collaborative. One thousand, two hundred and thirty-three unique participants from 141 teams attended the six LSs. A total of 5,116 (59 \%) participants provided feedback after each LS across the six LS in five regions (Appendix K). The online follow-up survey response rates after LS4 $(n=469 ; 33 \%)$ and LS6 $(n=254 ; 21 \%)$ were low. Based on a 4.0 scale, mean scores for all satisfaction items and scales were identical or slightly higher for the later learning sessions (see Table 4 below).

We report here on the combined follow-up surveys (723 unique responses, or $57 \%$ of Collaborative participants), including physicians (14\%), nurses (37\%), administrators (21\%), associated health professionals (6\%), and leadership participants $(21 \%)$ with VA experience ranging from 1 to 18 years (Appendix L). Participants reported success in gaining new skills and accomplishing learning objectives. $98 \%$ of respondents reported that they developed new skills/knowledge as a result of partici- pating in PACT Collaborative (Appendix M). Participants tended to be satisfied after each LS (Table 4) and regional Collaborative (Appendix N). Improvements included: $49 \%$ increase in team-led huddles per week; $38 \%$ increase in team meetings per month; $35 \%$ contact with patient within $48 \mathrm{~h} / 7$ days after discharge from inpatient care (Appendix O).

PACT Collaborative Evaluation. Ninety-one percent of respondents reported that the PACT Collaborative was necessary to implement PACT (91\%); the format was a helpful (86\%); they gained expected knowledge (93\%), developed (92\%) and shared (93\%) successful strategies, and called it a good networking opportunity (91 \%) (Appendix P). Additionally, $82 \%$ agreed that they had a clear understanding of their own and team members' roles; however, only $61 \%$ reported having the necessary influence to make changes needed at their home sites (Appendix Q).

\section{Usefulness of PACT Collaborative Resources}

Ninety-one percent reported their knowledge and understanding of how to implement PACT increased (ranged from 50 to $100 \%$ ) based on their participation in the Regional PACT Collaborative (Appendix R). Eighty-two percent reported that the resources and tools provided in 
Table 4. Participants' Assessment at the End of Each Learning Session

\begin{tabular}{|c|c|c|c|c|c|c|c|}
\hline & Item & LS1 & LS2 & LS3 & LS4 & LS5 & LS6 \\
\hline \multirow[t]{11}{*}{ Participant satisfaction } & Teaching strategies & 3.40 & 3.32 & 3.35 & 3.36 & 3.41 & 3.42 \\
\hline & Faculty up to date & 3.45 & 3.41 & 3.40 & 3.39 & 3.46 & 3.44 \\
\hline & Appropriate materials & 3.10 & 3.04 & 3.16 & 3.18 & 3.27 & 3.38 \\
\hline & Media functioned & 3.46 & 3.50 & 3.49 & 3.43 & 3.45 & 3.49 \\
\hline & Logistics timely & 3.30 & 3.19 & 3.03 & 3.23 & 3.28 & 3.23 \\
\hline & Logistics complete & 3.37 & 3.31 & 3.27 & 3.31 & 3.35 & 3.47 \\
\hline & Accommodations & 3.18 & 3.21 & 3.21 & 3.15 & 3.23 & 3.41 \\
\hline & Worthwhile & 3.56 & 3.49 & 3.47 & 3.43 & 3.50 & 3.54 \\
\hline & Compared favorably & 3.44 & 3.37 & 3.38 & 3.34 & 3.41 & 3.46 \\
\hline & Recommend & 3.46 & 3.39 & 3.39 & 3.37 & 3.46 & 3.53 \\
\hline & MEAN SCORE (4.0 Scale) & 3.37 & 3.32 & 3.32 & 3.32 & 3.38 & 3.44 \\
\hline \multirow[t]{4}{*}{ Participant learning } & Objectives relevant & 3.56 & 3.46 & 3.45 & 3.44 & 3.51 & 3.51 \\
\hline & Objectives match goals & 3.62 & 3.52 & 3.50 & 3.51 & 3.55 & 3.56 \\
\hline & Accomplished objectives & 3.36 & 3.29 & 3.30 & 3.32 & 3.38 & 3.44 \\
\hline & MEAN SCORE (4.0 Scale) & 3.51 & 3.42 & 3.42 & 3.42 & 3.48 & 3.50 \\
\hline \multirow[t]{4}{*}{ Achievement of objectives } & Developed skills & 3.37 & 3.30 & 3.30 & 3.28 & 3.33 & 3.44 \\
\hline & Competent to apply & 3.38 & 3.29 & 3.35 & 3.36 & 3.42 & 3.44 \\
\hline & Able to use skills & 3.41 & 3.33 & 3.35 & 3.34 & 3.42 & 3.44 \\
\hline & MEAN SCORE (4.0 Scale) & 3.39 & 3.31 & 3.33 & 3.33 & 3.39 & 3.44 \\
\hline
\end{tabular}

the PACT Collaborative were useful in implementing changes, and $79 \%$ reported that the resources and tools were helpful in sharing information at their facilities. Respondents rated the following resources from "slightly useful" to "extremely useful": coaching (95\%), regional Microsoft LiveMeeting/conference calls (95\%), Prework Guide (97\%), change package (98\%), Collaborative coordinators (97\%), Collaborative directors (96\%), IEs (84\%), standardized measurement tools (90\%), and monthly reports (92\%) (Appendix S).

\section{Barriers and Enablers}

The most common enablers included: opportunities to practice and use the skills learned $(65 \%)$, usefulness of skills/behaviors (72\%), senior leadership support (45\%), supervisor support (59\%), impact on career development goals (56\%), support from local PACT teams (71\%), productivity of local PACT teams (72\%), customer support (58\%), VHA's commitment (60\%), priority level (58\%), and confidence to use the process (65\%). Barriers included availability of coaching assistance $(50 \%)$ and availability of measurement support (45\%) (Appendix T).

\section{PACT Collaborative Success Factors}

Respondents reported the following PACT Collaborative success factors: recruiting the right people on the PACT team (82\%), setting clear and mutually agreeable aim statements $(88 \%)$, establishing simple measures (87\%), flow mapping processes $(83 \%)$, reporting teams' progress toward aims (83\%), conducting PDSA cycle tests of change (79 \%), obtaining buy-in from others in the organization to successfully implement recommended changes $(77 \%)$, and spreading PACT to other teams at the facility (82\%) (Appendix U).

\section{Participants' Perspectives on Change}

Respondents reported the information received about PACT changes had been timely (68\%), was useful (78\%), and allowed them to participate in the implementation of the 
proposed changes $(71 \%)$. Respondents reported that the PACT Collaborative adequately answered their questions about the changes $(60 \%)$, allowed them to ask questions about proposed changes (69 \%), and was more effective than past efforts (59\%). Respondents reported that adequate information was provided about the forthcoming changes (55\%), and that they had some control over implementing the proposed/occurring changes (54\%). (Appendix V).

\section{DISCUSSION}

The traditional BTS Collaborative includes three LS and lasts less than 12 months; VHA's PACT Collaborative consisted of six LSs and lasted 21 months. Teams adopted PSDAs at a steady rate, where the majority of PDSAs were accomplished in the second half of the Collaborative. The slow increase of PDSAs during the first half of the Collaborative may reflect the teams' formation, learning improvement methods, and challenges to implement aims. The timing of PDSA completion to achieve Collaborative aims suggests that for a complex intervention like PACT, the longer timeline may be a better match for Quality Improvement project completion in the PACT environment.

The majority of participants considered the Collaborative to be necessary for successful PACT implementation. Collaborative coaches judged most PDSA cycles as successful for PACT pillars; participants reported behavior change stemming from Collaborative activities. While the specific effects of the Collaborative cannot be separated from the many other implementation strategies employed by VA, the overall significant national PACT improvement in the specific areas addressed by the Collaborative and in line with the Collaborative's time line may have been influenced by the large-scale Collaborative process.

While participants valued the Collaborative overall, the data collected identifies several areas for further investigation and improvement. Improving handovers between PACT and its affiliated inpatient and specialty services proved especially challenging for improvement teams. Nearly half of participants did not feel empowered to make changes, and a majority did not feel they had input into decisions about their organization's future. Pilot teams' organizational influence may be important to the VHA's ability to achieve improved performance. Future investigation of these findings may be important to PACT and its ability to achieve an ongoing improvement-oriented culture.

\section{LIMITATIONS AND FUTURE DIRECTIONS}

The analyses presented here are formative and not designed to address the effectiveness of Collaboratives. VHA's PACT
Collaborative was part of a larger organizational strategy that included resource infusion, system-wide performance goals, and complementary approaches to education. For this reason, it is difficult to ascribe the level of contribution made by the Collaborative effort to VHA's progress in PACT implementation. Other limitations include: Coach Assessment scores are subjective, and PACT Compass scores reflect all PACTs, not the subgroup of Collaborative participants. The survey response rate was $59 \%(723 / 1233)$ and dropped to $21 \%$ for the last survey. Levels of satisfaction remained stable across survey waves; the non-responders, however, may have been more or less satisfied than the responders.

Since the PACT Collaborative, the skills, PACT toolkit, change and measure tools, and relationships created have been a valuable and reused resource, and many VA primary care practices have adopted the features of patient-centered care embodied by the PACT Collaborative. Achieving all the goals will involve continued strategic redeployment of resources, realignment of priorities, and continued cultural change toward the PACT mission to provide Veterans' healthcare delivery of the highest quality, safety, and effectiveness.

As the VHA continues to disseminate the PACT Model through primary care and address improvements in specialty/surgical care and mental health, the Collaborative Learning Model may be an effective way to begin to create change across a large system.

\section{CONCLUSION}

The VHA PACT Collaborative - one of the largest and longest conducted to date - was implemented in a highly standardized and disciplined manner. Participants reported positive feedback; written reports and measures documented progressively increasing numbers of changes; and coaches assessed that teams achieved most of their aims. Moreover, the PACT Compass measures reported whole system improvements in PACT performance measures. This carefully designed and executed VHA PACT Collaborative was an effective component of the overall VHA strategy of implementing wide-scale transformation in primary care for Veterans.

Acknowledgements: The authors gratefully acknowledge Gordon Schectman, MD, Chief Consultant, Primary Care Services, VA Central Office; Joanne M. Shear MS, FNP-BC, Primary Care Clinical Program Manager, Offices of PC Operations \& PC Policy VA Central Office; and all Regional PACT Steering Teams, Leadership Teams, VERC Industrial Engineers, Coaches and Facilitators for their work in carrying out the Collaborative.

Funders: The work described was funded and led by the Department of Veterans Affairs Office of Systems Redesign and Primary Care Operations.

Conflict of Interest: Dr. Bidassie, Dr. Davies and Dr. Stark are employed full time by the Department of Veterans Affairs. Ms. Boushon, a private healthcare consultant, was employed part time 
by VA for this project. All authors have declared no potential conflicts of interests with respect to the authorship, research and commercial value of publishing this article.

The views expressed within are solely those of the authors and do not necessarily represent the views of the Department of Veterans Affairs or the United States government.

Corresponding Author: Balmatee Bidassie, $\mathrm{PhD}$; Clinical Partnerships in Healthcare Transformation (CPHT), VA Center for Applied Systems Engineering (VA-CASE), VISN11 - Veterans Engineering Resource Center (VERC), Detroit, MI, USA (e-mail: balmatee.bidassie@va.gov).

\section{REFERENCES}

1. Solimeo SL, Hein M, Paez M, Ono S, Lampman M, Stewart GL. Medical homes require more than an EMR and aligned incentives. Am J Manag Care. 2013;19(2):132-40.

2. Primary Care. Available at: http://en.wikipedia.org/wiki/Primary_care. Accessed January 3, 2014.

3. Thomas-MacLean R, Tarlier D, Ackroyd-Stolarz S, Fortin M, Stewart M. No Cookie-Cutter Response: Conceptualizing Primary Health Care. Available at: http: / /www.uwo.ca/fammed/csfm/tutor-phc/documentation / trainingpapers/TUTOR_Definitio_\%20of_primar_\%20health_care.pdf. Accessed January 3, 2014

4. World Health Organization. Definition of Terms. 2011.

5. Longman P. Best Care Anywhere: Why VA Health Care Is Better Than Yours, April 2010.

6. Plsek P. "Complexity and the Adoption of Innovation in Health Care" AHRQ, 2003.

7. Grundy P. Doctor's Digest: Primary Care and the Medical Home. May/ June 2009.

8. Hoff T, Weller W, DePuccio M. The Patient-Centered Medical Home: A Review of Recent Research. Med Care Res Rev. 2012;69(6):619-44.

9. Shi BS, Yu L. The Medical Home, Access to Care, and Insurance: A Review of Evidence. Pediatrics. 2004;113:1493-8.

10. Fifield J, Forrest DD, Burleson JA, Martin-Peele M, Gillespie W. Quality and Efficiency in Small Practices Transitioning to Patient Centered Medical Homes: A Randomized Trial. J Gen Intern Med, 2013.

11. Raphael JL, Rattler TL, Kowalkowski MA, Mueller BU, Giordano TP. The medical home experience among children with sickle cell disease. Pediatr Blood Cancer. 2013;60(2):275-80.

12. Berdine HJ, Skomo ML. Development and integration of pharmacist clinical services into the patient-centered medical home. J Am Pharm Assoc. 2012;52(5):661-7.

13. Council LS, Geffken D, Valeras AB, Orzano AJ, Rechisky A, Anderson S. A medical home: changing the way patients and teams relate through patient-centered care plans. Fam Syst Health. 2012;30(3): 190-8.
14. True G, Butler AE, Lamparska BG, Lempa ML, Shea JA, Asch DA, Werner RM. Open access in the patient-centered medical home: lessons from the Veterans Health Administration. J Gen Intern Med. 2012.

15. Klein S. The Veterans Health Administration: Implementing PatientCentered Medical Homes in the nation's largest integrated delivery system. Commonwealth Fund. 2011;16:1537-60.

16. Rosland A-M, Nelson K, Sun H, Dolan E, Maynard C, Bryson C, Stark R, Shear JS, Kerr E, Fihn SD, Schectman G. The Patient-Centered Medical Home in the Veterans Health Administration. Am J Manag Care. 2013;19(7):e263-72.

17. American Academy of Family Physicians (AAFP), American Academy of Pediatrics (AAP), American College of Physicians (ACP), American Osteopathic Association (AOA). Joint Principles of the Patient-Centered Medical Home. Available at: http://www.aafp.org/dam/AAFP/documents/practice_management/pcmh/initiatives/PCMHJoint.pdf. Accessed January 3, 2014

18. Carrier E, Gourevitch MN, Shah NR. Medical homes: challenges in translating theory into practice. Med Care. 2009;47(7):714-22.

19. Reid RJ, et al. Patient-centered medical home demonstration: a prospective, quasi-experimental, before and after evaluation. Am J Manag Care. 2009;15(9):e71-87.

20. The Robert Graham Center. The Patient Centered Medical Home: History, Seven Core Features, Evidence and Transformational Change. Available at: http://www.graham-center.org/online/etc/medialib/graham/documents / publications/mongraphs-books/2007/rgcmo-medicalhome.Par.0001. File.tmp/rgcmo-medical-home.pdf. Accessed January 3, 2014

21. Hurtado MP, Swift EK, Corrigan J, eds. Envisioning a national health care quality report (US). Institute of Medicine. Washington: National Academy Press; 2001. Available at: http://www.nap.edu/ catalog.php?record_id=10073\#toc. Accessed January 3, 2014.

22. American College of Physicians. The Advanced Medical Home: A PatientCentered, Physician-Guided Model of Health Care. 2006. Available at: http://www.acponline.org/advocacy/events/state_of_healthcare/ statehc06 5.pdf. Accessed January 3, 2014.

23. Davies, ML. Systems Redesign Framework for Improvement (TAMMCS), 2009

24. Institute for Healthcare Improvement. The Breakthrough Series: IHI's Collaborative Model for Achieving Breakthrough Improvement. 2003.

25. Boushon B, Provost L, Gagnon J, Carver P. Using a virtual breakthrough series collaborative to improve access in primary care. Jt Comm J Qual Patient Saf. 2006;32(10):573-84.

26. VHA Systems Redesign Program Office. Patient Centered Medical Home Collaborative Prework Guide. 2010

27. PACT Toolkit. https://vaww.visn11.portal.va.gov/sites/VERC/va-case/ info/PACTToolkit/SitePages/Home.aspx. Accessed January 3, 2014

28. Institute for Healthcare Improvement. The Breakthrough Series: IHI's Assessment Scale for Collaborative. 2004.

29. Medical Home Builder Survey VISN Detail. Available at: https:// securereports 2.vssc.med.va.gov/ReportServer/Pages / ReportViewer.aspx?\%2fPC\%2fPC+Medical+Home\%2fMainMenu\&rs\%3aCommand=Render. Accessed January 3, 2014.

30. Veterans Health Administration, Employee Education System. PACT Program Evaluation \& Measurement Unit 2012. 